\title{
New experimental techniques for dynamic crack localization
}

\author{
David Grégoire - Hubert Maigre — Fabrice Morestin \\ Université de Lyon, CNRS \\ INSA-Lyon, LaMCoS UMR5259 \\ Bât. J. D'Alembert, 18-20 rue des Sciences \\ F-69621 Villeurbanne \\ david.gregoire@ens-cachan.org
}

\begin{abstract}
The determination of relevant constitutive crack propagation laws under dynamic loading is a rather challenging operation. In dynamic impact cases, the variations of propagation parameters and exact crack positions are difficult to control. This paper focuses on different techniques for measuring accurate crack tip position histories in dynamic crack propagation experiments. Two different methods are considered: very accurate crack tip localization by optical displacement sensors is first described for transparent materials; then, an automatic method based on digital image correlation is presented for crack localization in all brittle materials whatever their opacity.

RÉSUMÉ. L'obtention de lois pertinentes de propagation dynamique de fissures reste délicate. Dans les cas d'impacts dynamiques, l'évolution des paramètres de rupture et la position exacte de la fissure sont difficiles à contrôler. Ce papier présente différentes techniques pour mesurer précisément la position du front d'une fissure dans le cas d'expériences de propagation dynamique. Une méthode de localisation très précise du front de fissure en utilisant un capteur optique de déplacement est tout d'abord décrite pour des matériaux transparents. Ensuite, une méthode automatique basée sur la corrélation d'images numériques est présentée pour la localisation de fissure dans tout matériau fragile, quelle que soit son opacité.

KEYWORDS: dynamic fracture, mixed mode loading, crack localization, digital image correlation, crack arrest and restart.

MOTS-CLÉS: rupture dynamique, mode mixte, localisation de fissure, corrélation d'image numérique, arrêt et redémarrage de fissure.
\end{abstract}

DOI:10.3166/EJCM.18.255-283 (c) 2009 Lavoisier, Paris 


\section{Introduction}

The risks due to crack propagation under dynamic loading are still difficult to estimate. Unlike quasi-static cases, where the loading and crack position can be easily established, in dynamic impact cases, loading conditions, propagation parameter variations and exact crack positions are difficult to control. The determination of relevant constitutive crack propagation laws from dynamic crack propagation experiments is thus a challenging operation. Consequently, the first step for assessing dynamic crack propagation laws is the development of numerical simulation tools. Some numerical tools are now able to represent dynamic crack growth but these numerical results have to be compared with experimental results to ensure that the numerical laws introduced are physically consistent.

Although many experiments have already been carried out, obtaining experimental results in dynamic crack propagation cases under mixed-mode loading is still difficult. The accurate measurement of the velocity of a crack under highly transient mixed-mode conditions is problematic. Strain gages (Owen et al., 1998), thin metal layer evaporated onto one specimen face (Fineberg et al., 1991; Stalder et al., 1983), common electrical or optical techniques are traditionally used with contrasted results.

In a previous work (Grégoire et al., 2007), crack tip position histories have been determined by standard optical tools. The test rig was a split Hopkinson pressure bar (SHPB) and the specimen geometry was chosen in order to provide direct conversion between impacting compressive waves and tensile waves in the vicinity of a machined notch. Since the material used (PMMA) was transparent, four cameras with a very short exposure time, connected through a delay line, were used to provide pictures of the propagating crack tip. By checking that the results were highly reproducible, five experimental tests were carried out by shifting the different shooting times. All crack tip positions were collected to obtain the crack tip position history. Three different phases were observed: two propagation phases were separated by a crack arrest phase. These three phases occurred during a highly transient phase and these conditions provided a challenging test of the reliability of the numerical simulations. Using an eXtended Finite Element Method (XFEM), numerical simulations were performed and both the crack path and the crack position histories fitted the experimental results.

This kind of comparison allowed the validation of a dynamic crack growth criterion but only in a unique case of loading. The next step in the dynamic crack propagation laws assessment should be to show how the dynamic crack growth criterion depends on the loading conditions. However, with standard optical tools such as cameras, the previous process leads to a large experiments number for obtaining different crack tip position histories corresponding to different loading rate. Moreover the loading rate influence on the transient propagation phases as arrest and restart cannot be represented accurately if several experiments are needed to obtain a crack tip position history. Therefore new experimental methods are required to assess relevant constitutive crack propagation laws from experiment. 
Firstly, a very accurate crack tip localization method using an optical displacement sensor is presented for transparent materials. Secondly, an automatic crack localization method based on digital image correlation is described for all brittle materials whatever their opacity.

\section{Crack tip localization using the optical displacement sensors}

\subsection{Description of the test rig and the specimen}

The test rig is a split Hopkinson Pressure Bar (SHPB) test developed by Kolsky (1949) and primarily used for the measurement of a material dynamic behavior. It is schematized in Figure 1. The test specimen is made of polymethylmethacrylate (PMMA), a transparent brittle material. The mechanicals properties of nylon and PMMA are quite similar. Therefore, the bars are chosen made of nylon in order to guarantee both a good wave transmission on their interfaces with the specimen and an elastic strain gage response. Details on the experimental setup are presented in (Grégoire et al., 2007).

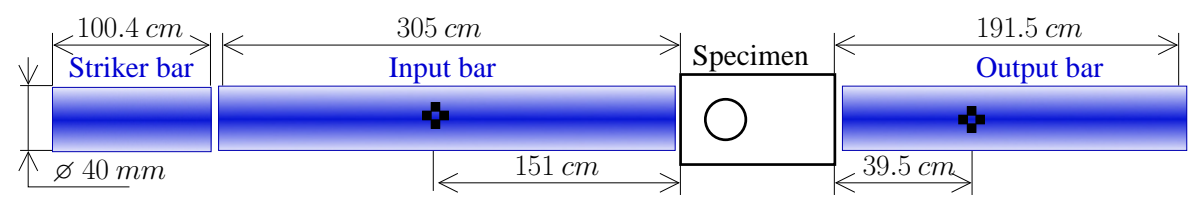

Figure 1. Test rig

There is no standard for dynamic fracture tests. Therefore a simple, but distinctive, geometry designed is chosen to obtain transient propagation phases as crack arrest and restart. The compressive waves must be converted into tensile waves, in order to obtain fracture opening modes at the crack tip. Therefore, a rectangular specimen with a circular hole is used to provide both the direct wave conversion without producing any friction at the specimen-bars interfaces and the crack arrest zone. An initial notch is machined at the border of the hole in order to initiate the crack as shown in Figure 2. Fracture occurs in pure mode I when the initial notch is machined on the specimen symmetry axis.

\subsection{Measurement}

The use of SHPB is attractive in our case because it provides both an accurate measurement of the applied loading and the global response of the test specimen during the transient experiment, thus enabling good control of the quality of the experimental tests. Reliable experimental data is necessary to ensure that the simulations are physically meaningful. This is one of the keys to success in comparing numerical simulations with experiments. 

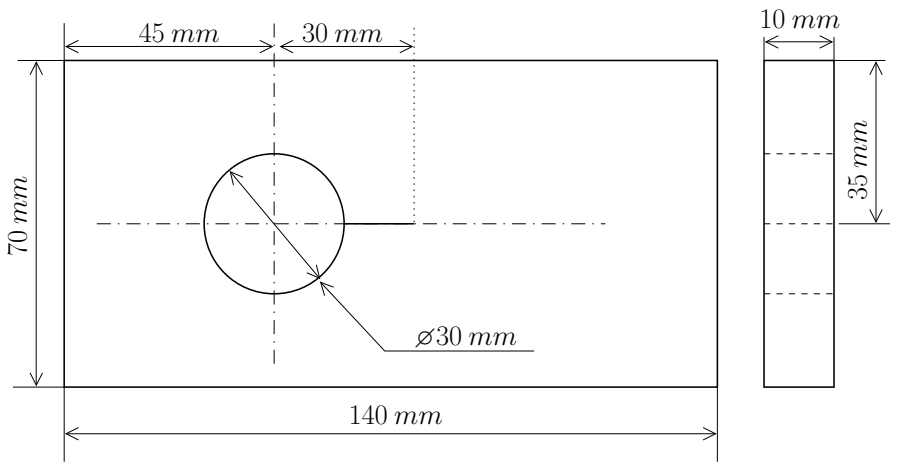

Figure 2. Specimen geometry under pure mode I loading condition

Figure 3 shows a sketch of the test rig. One can identify:

- the striker bar, input bar and output bar and the specimen between the bars;

- 2 strain gages connected to their amplifiers;

- 1 optical displacement sensor:

Zimmer $100 \mathrm{H}$ - 116: measuring range $20 \mathrm{~mm}$, working distance $41.1 \mathrm{~mm}$;

- 1 standard light;

- 1 data acquisition adapter ( 4 channels, $1 \mathrm{MHz}$ );

-1 optical sensor connected to an oscilloscope;

-2 computers.

Since PMMA is transparent, optical displacement sensors are used. A Zimmer extensometer converts the movement of a black and white target into an analogical signal $( \pm 5 \mathrm{~V})$ proportional to the displacement of the black and white contrasted border. The measurement range is determined by the adaptive lens. The Zimmer extensometer was primarily used to measure the macroscopic displacements of a body by sticking on it a black and white target. Since the light reflects on the crack path and passes through the specimen sound part, an analogical signal proportional to the crack tip position is obtained. The resolution, the working distance, the uncertainty and the width of the measure as well as the maximum tracking velocity depend on the measurement range linked to the lens choice. The characteristics of the optical displacement sensor are collected in Table 1.

The loading is adjusted via several experiment parameters: the striker bar velocity, length and shape enabled to control the amplitude, the duration and the shape of the loading. Two different experiments are performed with the specimen geometry corresponding to pure mode 1 initiation. The experimental conditions are described in Table 2. 


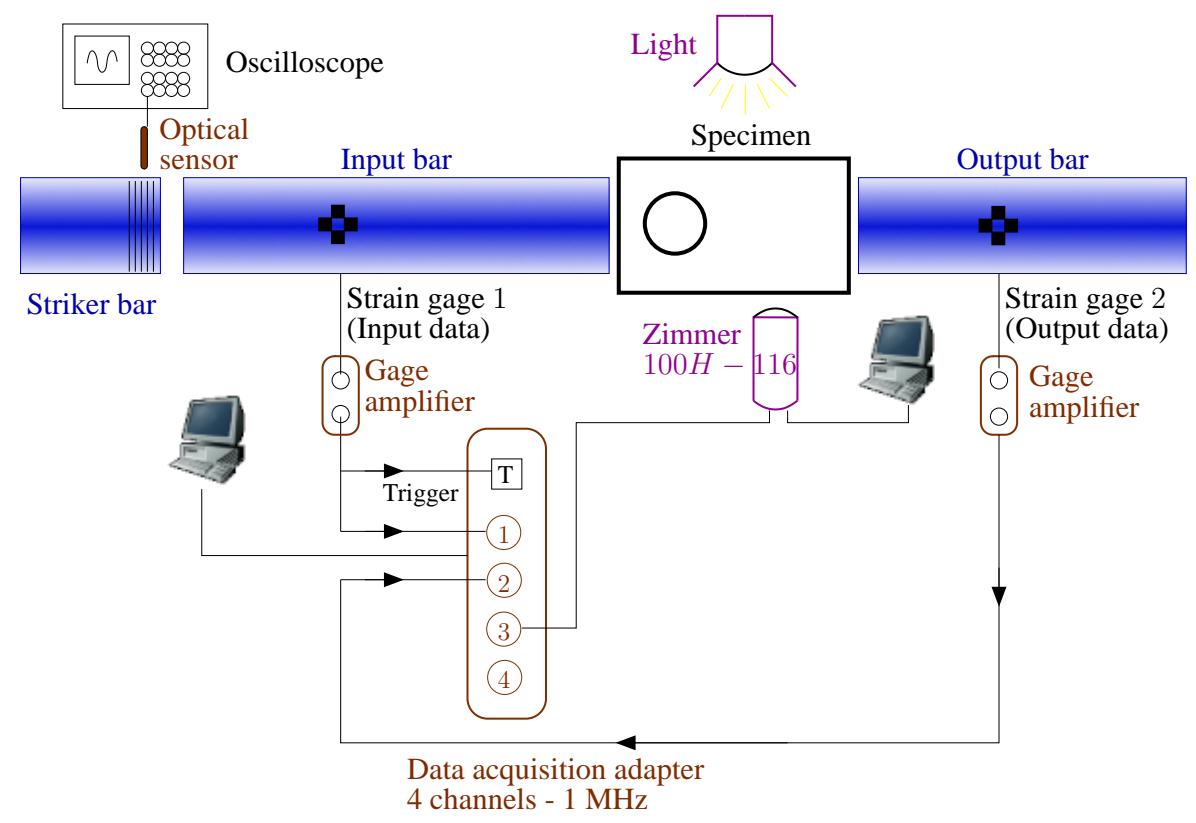

Figure 3. Experimental test rig (SHPB)

Table 1. Characteristics of the optical displacement sensors

\begin{tabular}{|c|c|}
\hline Zimmer & $100 \mathrm{H}-116$ \\
\hline \hline Measurement range & $20 \mathrm{~mm}$ \\
\hline Working distance & $41.1 \mathrm{~mm}$ \\
\hline Measurement width & $1 \mathrm{~mm}$ \\
\hline Resolution & $0.002 \mathrm{~mm}$ \\
\hline Uncertainty & $\pm 0.04 \mathrm{~mm}$ \\
\hline Maximum tracking velocity & $1670 \mathrm{~m} / \mathrm{s}$ \\
\hline
\end{tabular}

Table 2. Experimental conditions

\begin{tabular}{|c|c|c|c|}
\hline Experiment & Initiation & Striker length & Striker velocity \\
\hline \hline Test 1 & Mode 1 & $1.004 \mathrm{~m}$ & $9.5 \mathrm{~m} / \mathrm{s}$ \\
\hline Test 2 & Mode 1 & $1.004 \mathrm{~m}$ & $7.4 \mathrm{~m} / \mathrm{s}$ \\
\hline
\end{tabular}


To limit waves superposition, the gages are generally located at the middle of the bars (Figure 1). Consequently, the waves have to be shifted to the specimen-bar interfaces to obtain forces and velocities at the specimen faces. Waves dispersion and attenuation due to the viscous behavior of nylon and geometry effects are taken into account in the shifting as in (Zhao et al., 1995) in order to obtain more accurate measurements. The same process is performed for each experimental test. For instance, raw data corresponding to test 2 are shown in Figure 4.

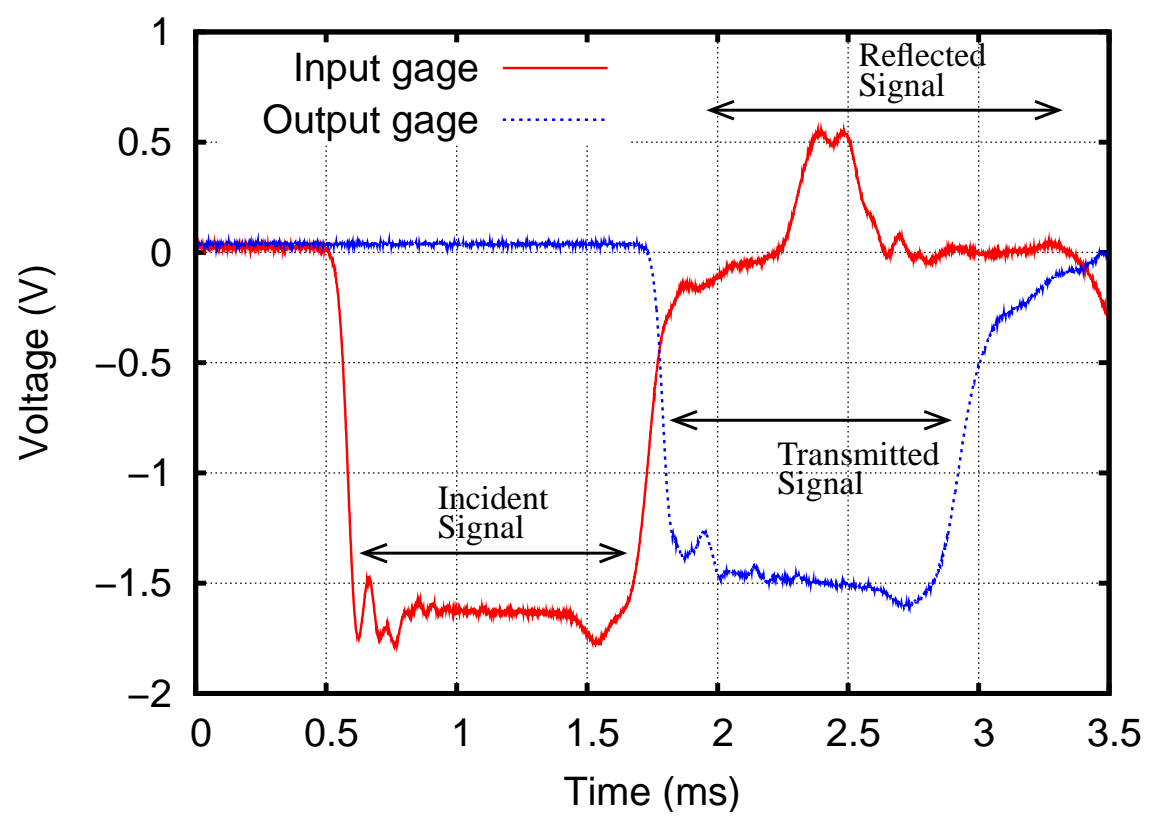

Figure 4. Unprocessed gage signals of test 2

\subsection{Results}

This section presents the experimental results obtained with the specimen geometry under pure mode 1 loading (see Figure 2). Two experiments have been performed with different impact velocities (Test 1 and test 2 in Table 2).

During these experiments, a Zimmer extensometer (see Table 1) have been used to obtain the crack tip position history. Since the measurement range is $20 \mathrm{~mm}$, the crack propagation history cannot be obtained entirely. The time when the optical displacement sensor starts producing a signal is chosen as the reference time. Furthermore, the X-coordinate reference corresponds to the left-hand face of the specimen (after the initiation, the crack grows from $x=75 \mathrm{~mm}$ ). 
Since the signal delivered by the extensometer takes into account the specimen solid body displacement in addition to the crack tip displacement, a correction is processed in order to obtain the real crack growth. Moreover, the extensometer signal is shifted in order to adjust the crack arrest with the position measured on the crack path postmortem view.

\subsubsection{Test 1 (Striker velocity: $9.5 \mathrm{~ms}$ )}

Figure 5 shows the propagating crack tip position history for the test 1 and three different propagation phases are observed:

- firstly, the crack grows at constant velocity $(V \approx 170 \mathrm{~m} / \mathrm{s}) ;$

- secondly, the crack stops during approximately $65 \mu \mathrm{s}$;

- finally, the crack restarts at constant velocity $(V \approx 180 \mathrm{~m} / \mathrm{s})$.

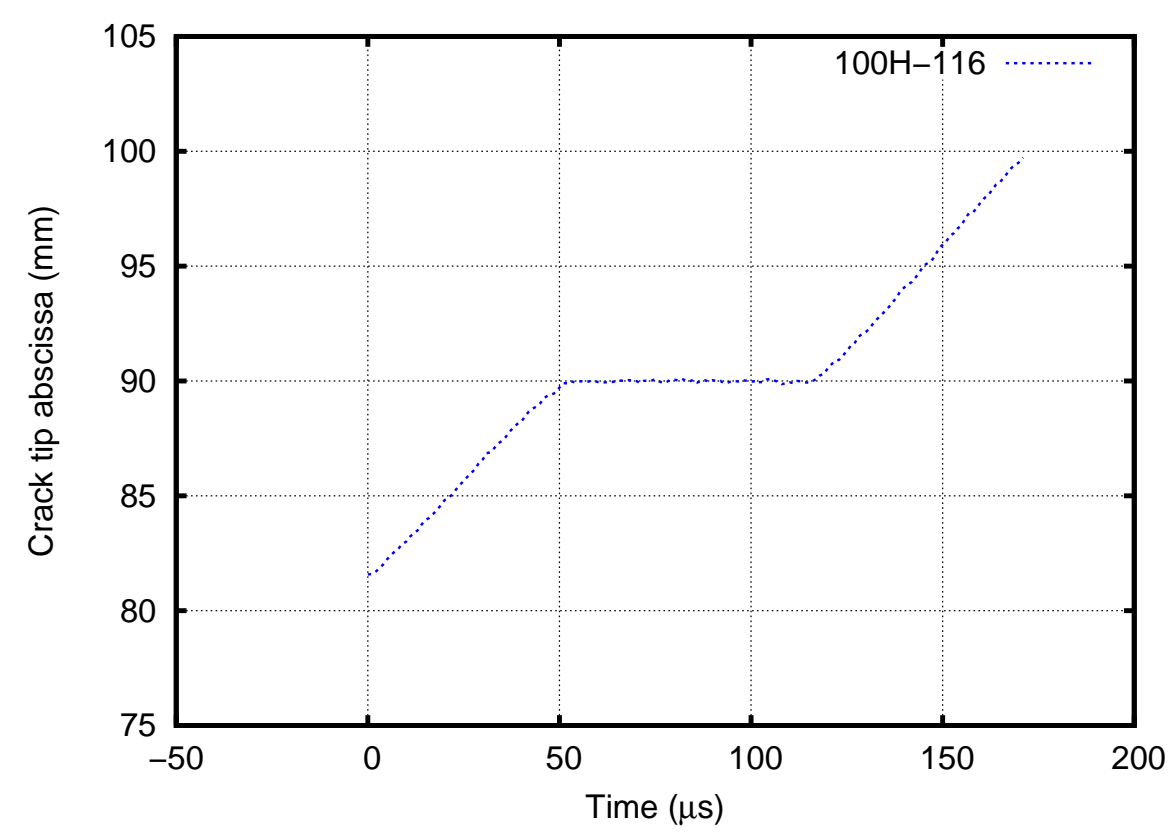

Figure 5. Crack tip position history for the test 1 (striker velocity: $9.5 \mathrm{~m} / \mathrm{s}$ )

Figure 5 reveals that this method based on optical displacement sensor measurement provides accurate crack tip localization, even during the highly transient propagation phases such as arrest and restart. Therefore, it is now possible to study the influence of the loading rate on these transient propagation phases. 


\subsubsection{Test 2 (Striker velocity: $7.4 \mathrm{~ms}$ )}

Since the initiation strongly depends on the initial notch shape, the experimental test 2 was performed in two stages. First, short crack propagation $(3.5 \mathrm{~mm})$ is obtained by impacting the specimen at a low velocity. Then, the specimen is submitted to a second higher impact. Therefore, the initial notch shape is similar to the propagating crack tip shape during the propagation. This technique can be linked to the fatigue crack growth initiation for metallic materials.

Figure 6 shows the propagating crack tip position history for the test 2 where the striker velocity was lower than the striker velocity of test 1 . Four crack arrests are now observed. After the initiation, the cracks grows during $22 \mu \mathrm{s}$ at a constant velocity of $(V \approx 150 \mathrm{~m} / \mathrm{s})$ and then stops during $17 \mu \mathrm{s}$. Afterwards, there are three short propagating phases separated by crack arrests before the final arrest. Therefore, this kind of experiment provides a challenging test of the reliability of the dynamic crack propagation numerical tools as well as a mean for assessing new constitutive crack propagation laws.

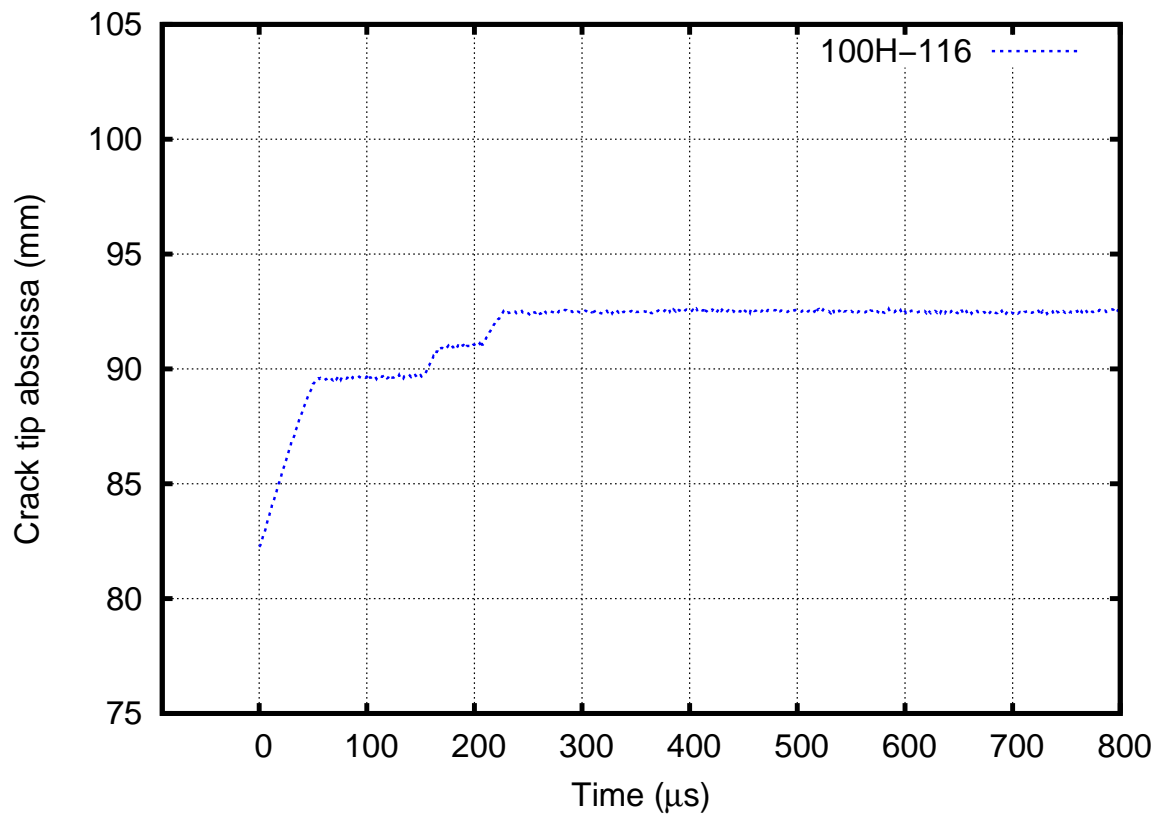

Figure 6. Crack tip position history for the test 2 (striker velocity: $7.4 \mathrm{~m} / \mathrm{s}$ )

Finally, a new experimental technique is developed for dynamic crack tip localization under mixed-mode loading in transparent materials. 


\subsection{Numerical comparison}

This section presents the numerical comparison with the experimental results obtained for the test 1 and 2 in pure mode 1 . The eXtended Finite Element Method is chosen for the simulations because the cracks are not described explicitly by the mesh. Furthermore, the implicit description of the crack geometry is compatible with any crack path, even if this path is a priori unknown. This method consists in using enrichment to the classical finite element approximation in order to capture the discontinuity and singularity of the strain field at the crack tip. It was first developed for quasi-static analysis in (Moës et al., 1999) and then used for dynamic crack propagation in (Grégoire et al., 2007) in the light of (Réthoré et al., 2005).

The numerical simulations are carried out using the input velocity collected from the experiments as a boundary condition at the input bar interface and an impedance condition is used to model the contact between the output bar and the specimen.

Even if the PMMA is known to be viscoelastic, a linear elastic behavior is assumed with a dynamic elastic modulus fitted with the velocity of the elastic waves measured during the experiments.

As developed in (Réthoré et al., 2005; Réthoré, 2005) a domain-independent integral is used to calculate dynamic stress intensity factors $\left(K_{I}^{d y n}, K_{I I}^{d y n}\right)$. Afterwards, the intensity of the loading near the crack tip $K^{*}$ and the preferential propagation direction $\theta^{*}$ are calculating using the Equations 1 and 1 as in (Grégoire et al., 2007).

$$
\begin{aligned}
& \theta^{*}=2 \arctan \left(\frac{1}{4}\left[\frac{K_{I}^{d y n}}{K_{I I}^{d y n}}-\operatorname{sign}\left(K_{I I}^{d y n}\right) \sqrt{8+\left(\frac{K_{I}^{d y n}}{K_{I I}^{d y n}}\right)^{2}}\right]\right) \\
& K^{*}=\cos ^{3} \frac{\theta^{*}}{2}<K_{I}^{d y n}>-\frac{3}{2} \cos \frac{\theta^{*}}{2} \sin \theta^{*} K_{I I}^{d y n}
\end{aligned}
$$

where $\left\langle K_{I}^{d y n}>\right.$, the positive part of $K_{I}^{d y n}$, avoids any closure effect.

Finally, the dynamic crack propagation criterion is:

$$
\begin{array}{rlll}
K^{*} & <K_{1 d} & & \text { (no initiation) } \\
K^{*} & =K_{1 d} & \text { (initiation) } \\
K^{*}>K_{1 a} & \Longrightarrow K^{*}(t, \dot{a})=\frac{K_{1 a}}{1-\left(\frac{\dot{d}}{c_{R}}\right)} & & \text { (propagation) }
\end{array}
$$

where $K_{1 d}$ is the dynamic crack initiation toughness, $K_{1 a}$ is the dynamic crack arrest toughness, $\dot{a}$ is the velocity of the crack tip and $c_{R}$ is the velocity of the Rayleigh waves, namely the theoretical maximum velocity of a crack in a homogeneous medium.

\subsubsection{Test 1}

The mesh is the same for each numerical test and it is shown in Figure 7. It consists of 1377 four-node elements with 4 integration points. The numerical calculation of the test 1 requires 120 time steps with a step size chosen as $\Delta t=5 \mu \mathrm{s}$. 


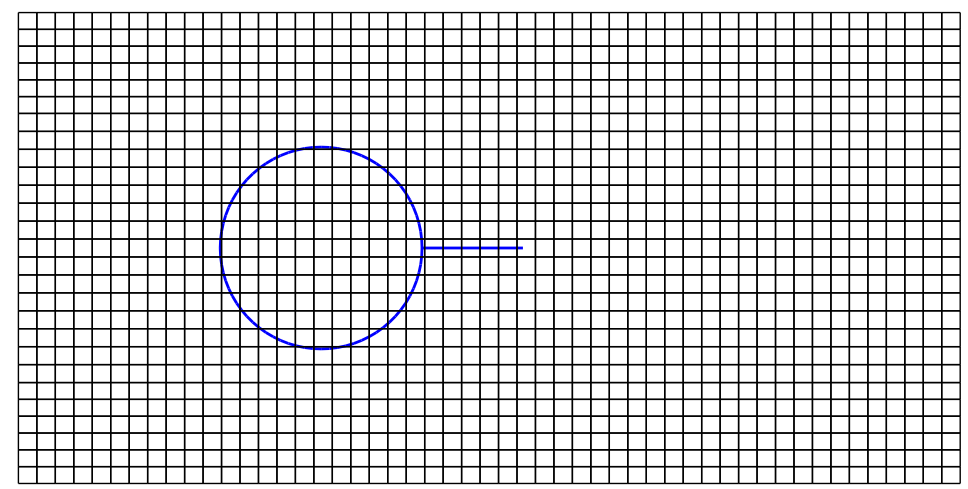

Figure 7. Mesh and initial notch for the test 1

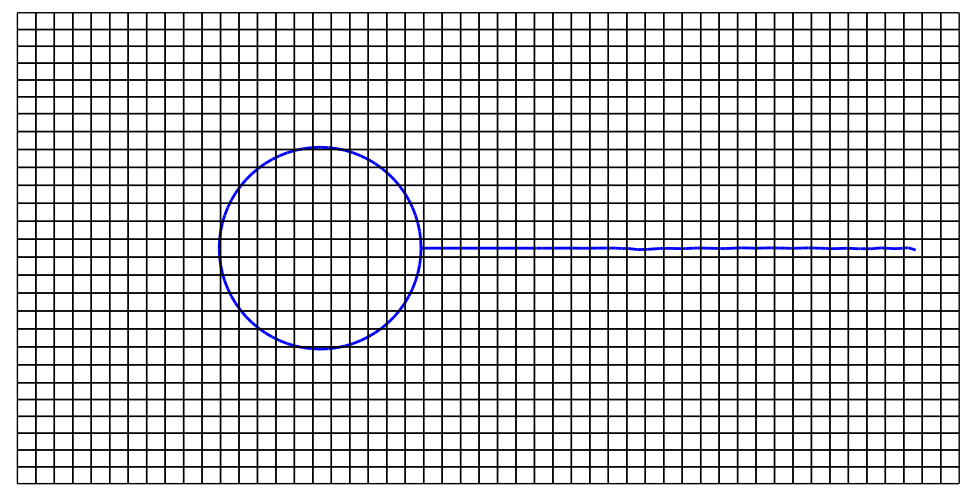

Figure 8. Mesh and numerical crack path for the test 1

The numerical crack path is shown in Figure 8. Since the initial notch is machined in such a way that fracture occurs in pure mode 1 , the crack stays near the specimen symmetry axis all over the propagation.

Figure 9 shows the comparison between the experimental and numerical crack tip position histories. The dynamic crack propagation criterion (Equation 3) have been used with $K_{1 d}=1.66 M P a \sqrt{m}$ and $K_{1 a}=1.22 M P a \sqrt{m}$. As explained in (Grégoire et al., 2007), the higher value of $K_{1 d}$ has two explanations: firstly, the radius of the initial notch tip is larger than the propagating crack tip radius in the experiments; secondly, the crack initiation point is intrinsically not on the curve characterizing the dynamic crack growth criterion: $\lim _{\dot{a} \rightarrow 0} K^{*}(t, \dot{a}) \neq K_{1 d}$ in Eq. 3 as it has been noticed by Ravi-Chandar (2004). 


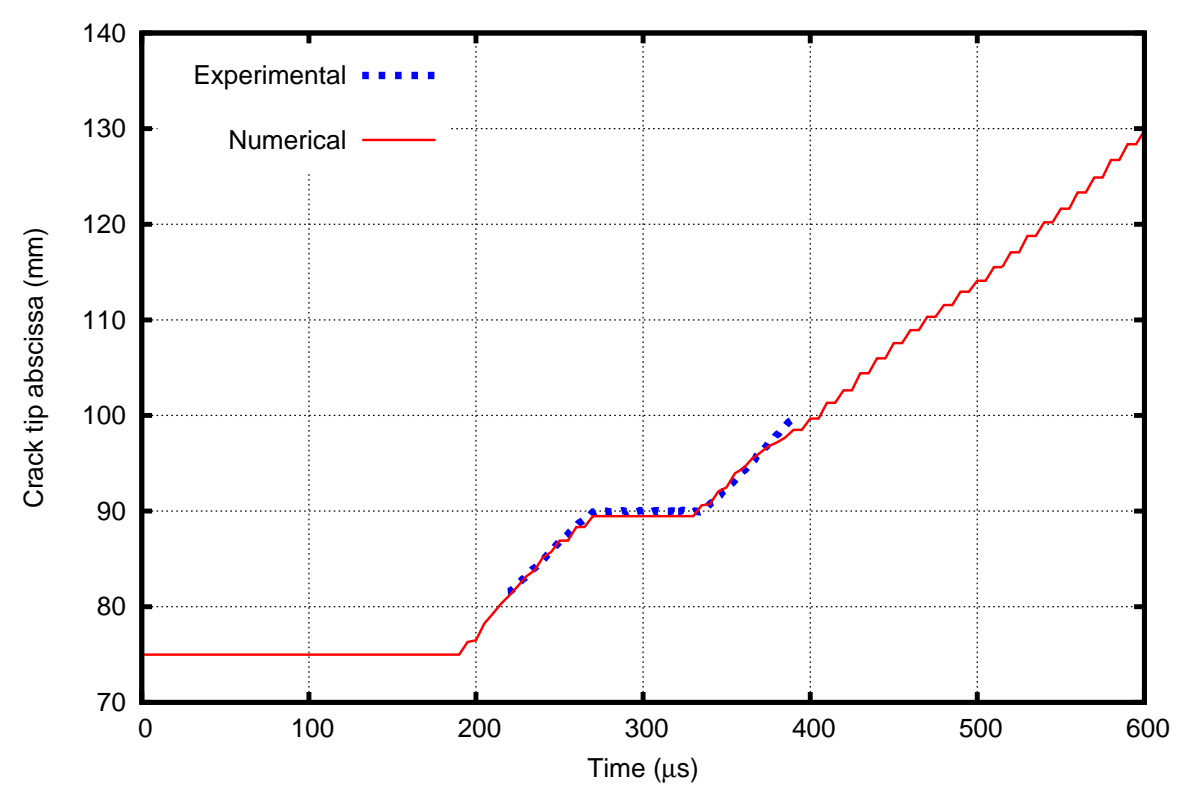

Figure 9. Comparison of crack tip position histories for the test 1

On Figure 9, there is a good matching of the crack position histories, even the crack arrests occurred at the same time and in the same location. However, before the crack arrest, the numerical crack position history is steeper than the experimental history. Therefore, the numerical velocity of the crack is too important during the first propagation phase and the criterion has to be improved.

\subsubsection{Test 2}

The mesh still consists of 1377 four-node elements with 4 integration points (Fig 10) but the initial notch is different from the test 1 in order to take into account the first propagation at low striker velocity as explained in part 2.3.2. The numerical calculation of the test 2 requires 200 time steps with a step size chosen as $\Delta t=5 \mu \mathrm{s}$.

The numerical crack path is shown in Figure 11. The crack still stays near the specimen symmetry axis all over the propagation but the final arrest occurs in the middle of the specimen.

Figure 12 shows the comparison between the experimental and numerical crack tip position histories. The dynamic crack propagation criterion (Equation 3 ) have been used with $K_{1 d}=0.95 M P a \sqrt{m}$ and $K_{1 a}=0.85 M P a \sqrt{m}$. Since the initial notch radius and the propagating crack tip radius are similar, the value of $K_{1 d}$ and $K_{1 a}$ are very close. It remains a difference because the crack initiation point is intrinsically 


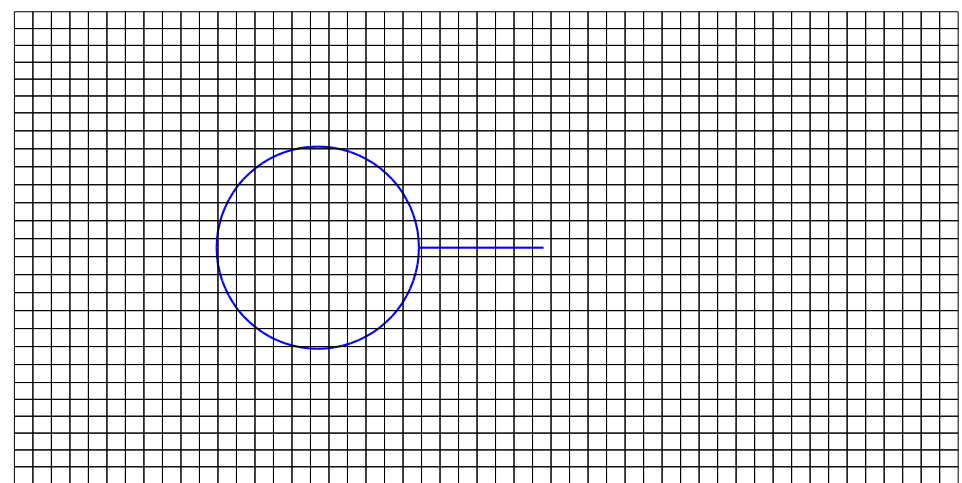

Figure 10. Mesh and initial notch for the test 2

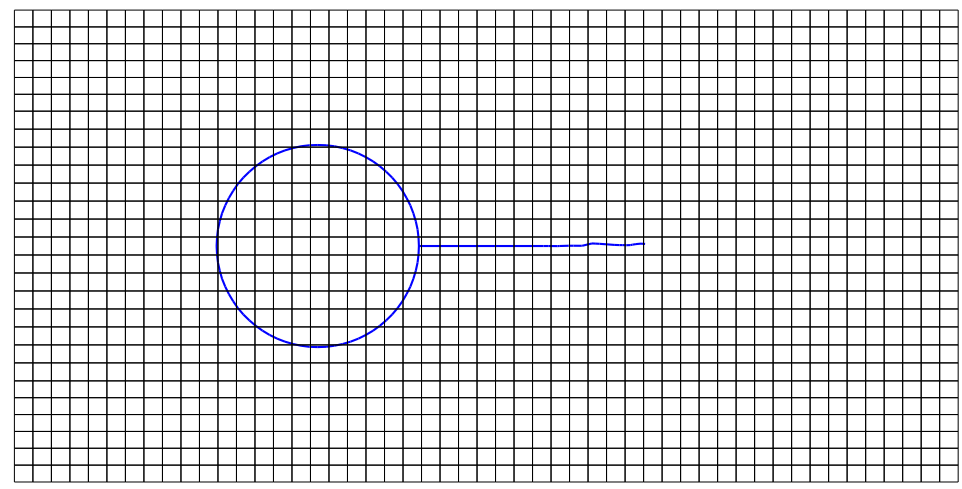

Figure 11. Mesh and numerical crack path for the test 2

not on the curve characterizing the dynamic crack growth criterion as explained by Ravi-Chandar (2004).

On Figure 12, there is a good matching of the crack position histories and the numerical and experimental first crack arrests occur at the same time and in the same location. The following crack arrests are well located in space but not in time. The criterion (Equation 3) is not enough accurate in order to well represent this complex phases similar to the stick-slip phenomenon. By only considering a macroscopic point of view, these results are already satisfying. 


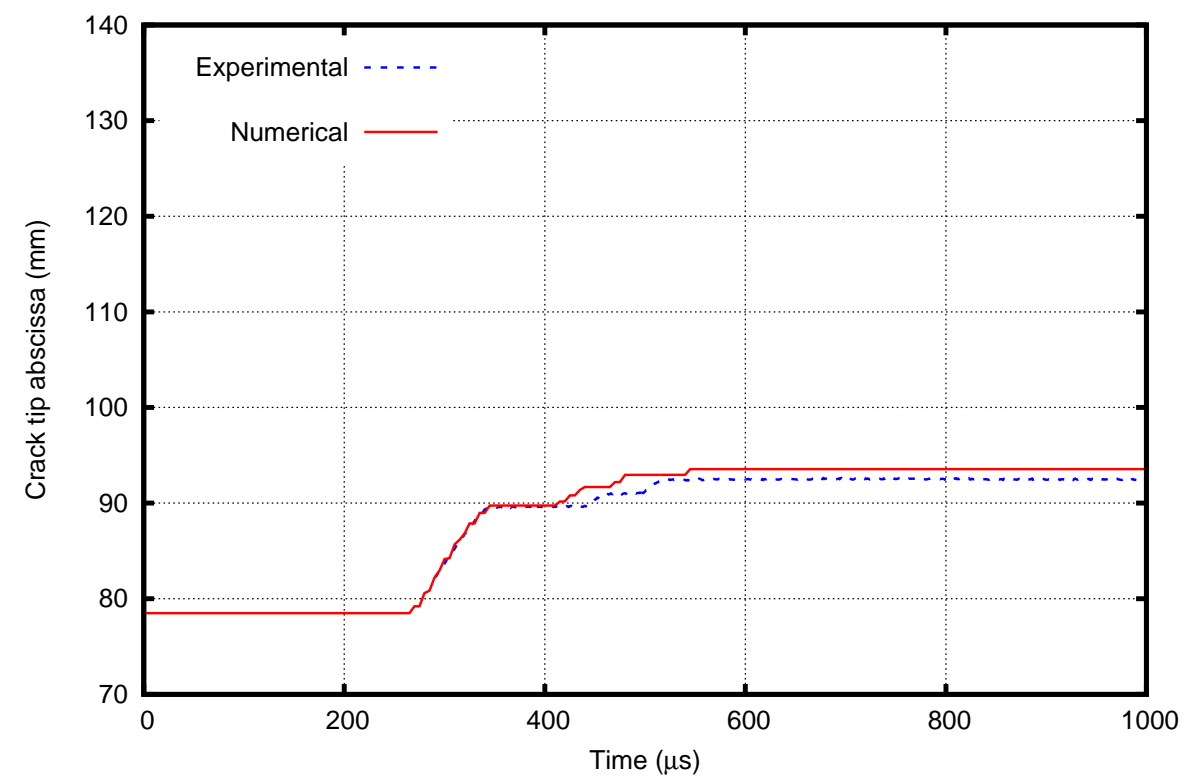

Figure 12. Comparison of crack tip position histories for the test 2

\section{Crack localization based on digital image correlation}

\subsection{General principle of digital image correlation}

The principle of image correlation was developed mainly by (Sutton et al., 1983; Sutton et al., 1986). Two digital images corresponding to a reference and a deformed state are described by a discrete function representing the grey level of each pixel. The discrete functions are related by the following relation:

$$
f^{*}\left(\mathbf{x}^{*}\right)=f(\mathbf{x}+\mathbf{d}(\mathbf{x}))
$$

where $f$ and $f^{*}$ are respectively the discrete functions of the reference and the deformed state and $\mathbf{d}(\mathbf{x})$ is the displacement field (Figure 13).

The optimal displacement field determination consists in the minimization of the cross-correlation coefficient on a set of initial image pixels (called a subset):

$$
C=1-\frac{\int_{\Delta M} f(\mathbf{x}) f(\mathbf{x}+\mathbf{d}(\mathbf{x})) \mathbf{d} \mathbf{x}}{\sqrt{\int_{\Delta M} f^{2}(\mathbf{x}) \mathbf{d} \mathbf{x} \int_{\Delta M} f^{2}(\mathbf{x}+\mathbf{d}(\mathbf{x})) \mathbf{d x}}}
$$

where $\Delta M$ is the initial image subset surface. 


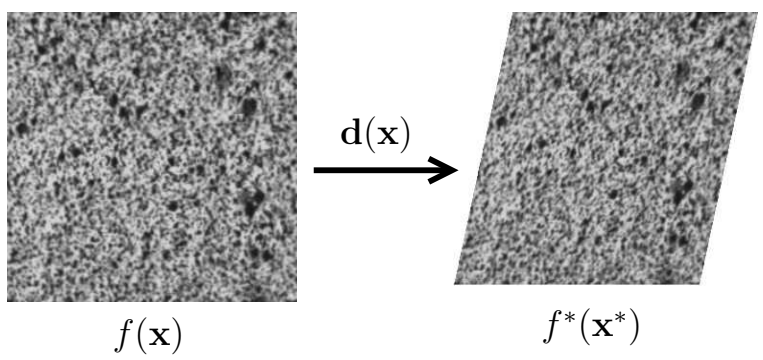

Figure 13. Reference and deformed images

The displacement field is then decomposing on an appropriate functional basis on a subset (Equation 6).

$$
\mathbf{d}(P)=\sum_{j} n_{j}(P) \mathbf{u}_{\mathbf{j}}
$$

where $u_{j}$ are the displacement unknown, $P$ is a point of the subset, $\mathbf{d}(P)$ is given by the minimization of Equation 5 and $\mathbf{n}_{\mathbf{j}}$ are the functions chosen.

According to the numbers of unknowns introduced in the decomposition, the Equation 6 is written as many times as needed to have a problem well-posed.

Finally, the problem consists in inverting a matrix (Equation 7).

$$
D=[\mathbf{M}] U
$$

where $D$ is the vector of the optimal displacements obtained by the minimization of Equation 5, $[M]$ is the matrix of the functional basis and $U$ is the vector of the displacements unknown.

In practice, a bilinear displacement field $\left(\left\{n_{j}\right\}=\{x, y, x y, 1\}\right)$ and a cubic spline interpolation are used as in (Touchal-Mguil, 1997). Figure 14 shows a subset before $\left(A B C D\right.$ centered on $P$ ) and after $\left(A^{*} B^{*} C^{*} D^{*}\right.$ centered on $\left.P^{*}\right)$ deformations on the same axis for better understanding.

For each point of a given subset, the displacement field is:

$$
\left\{\begin{array}{l}
d_{x}(x, y)=u_{1} \tilde{x}+u_{2} \tilde{y}+u_{3} \tilde{x} \tilde{y}+u_{4} \\
d_{y}(x, y)=u_{5} \tilde{x}+u_{6} \tilde{y}+u_{7} \tilde{x} \tilde{y}+u_{8}
\end{array}\right.
$$

where $\tilde{x}=\frac{x-x_{A}}{L}$ and $\tilde{y}=\frac{y-y_{A}}{L}$ are the homogeneous coordinates in a subset

Hence, there are eight unknowns $\left(u_{j}\right)$ and the Equation 8 is written for each point $A, B, C$ and $D$. The resolution consists in inverting the 8-dimensional matrix equation 7.

Finally, the algorithm is carried out on each subset of the initial figure in order to obtain the full-field displacement with a resolution of $1 / 100$ pixel. 

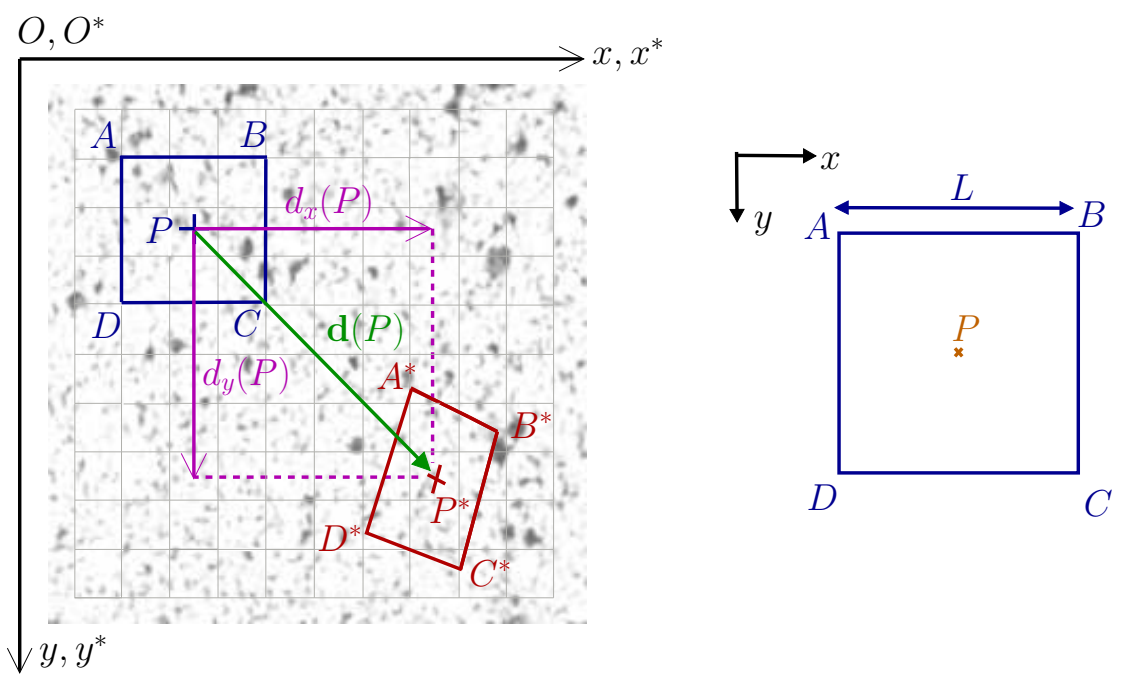

Figure 14. Initial subset and deformed subset

\subsection{Crack localization algorithm}

The latter image correlation technique is very efficient in order to obtain the fullfield displacement of a continuous body. Since the functional basis in Equation 6 contained only continuous terms, the method cannot evaluate the displacement field in case of a discontinuity (material or geometric). Hild et al. (2006) propose to enrich the functional basis with the linear fracture asymptotic functions in order to introduce a discontinuous term. Since the asymptotic displacement fields depend on the polar coordinate of the crack tip, the crack geometry has to be known to initiate the process. Here, a method based on digital image correlation is proposed in order to localize discontinuities even if there positions are totally unknown.

\subsubsection{General framework}

Two points $M$ and $N$ are considered in the reference image (Figure 15). Then, a displacement field, $\mathbf{d}(\mathbf{x})$, is applied in such a way that the corresponding points in the deformed image $\left(M^{*}\right.$ and $\left.N^{*}\right)$ are separated by a discontinuity.

A measurement of the discontinuity between the two points $M$ and $N$ is denoted $M \ll N$ and defined in Equation 9.

$$
M \gtrless N=\left\|\overrightarrow{M^{*} N^{*}}-\overrightarrow{M N}\right\|
$$




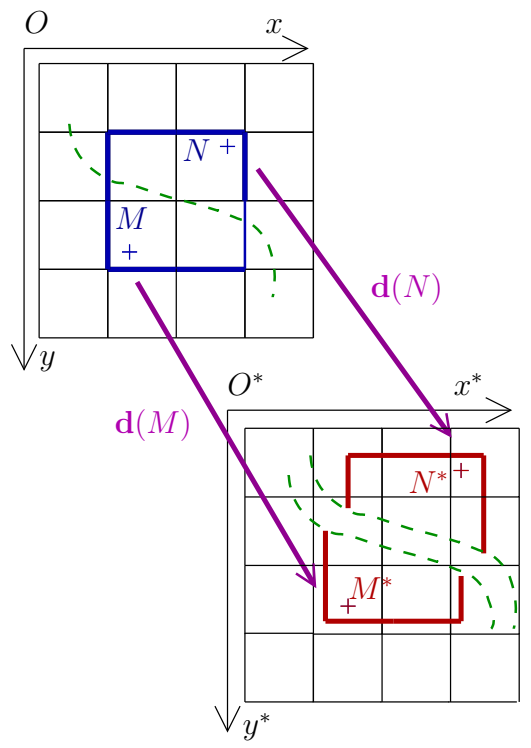

Figure 15. Discontinuity between two points $M$ and $N$

Therefore, since $\forall\left(M, M^{*}\right) \quad \overrightarrow{O^{*} M^{*}}=\overrightarrow{O M}+\mathbf{d}(M)$, the expression of the discontinuity between two points is rewritten in Equation 10.

$$
M \gtrless N=\|\mathbf{d}(N)-\mathbf{d}(M)\|
$$

where $\mathbf{d}(P)$ is still given by the minimization of Equation 5 .

From the latter definition of the discontinuity between two points (Equation 10), a criterion of discontinuity in a subset (Figure 14) is given in Equation 11.

$$
\begin{aligned}
K(P) & =\max (A \gtrless C ; B \gtrless D) \\
& =\max (\|\mathbf{d}(C)-\mathbf{d}(A)\| ;\|\mathbf{d}(D)-\mathbf{d}(B)\|)
\end{aligned}
$$

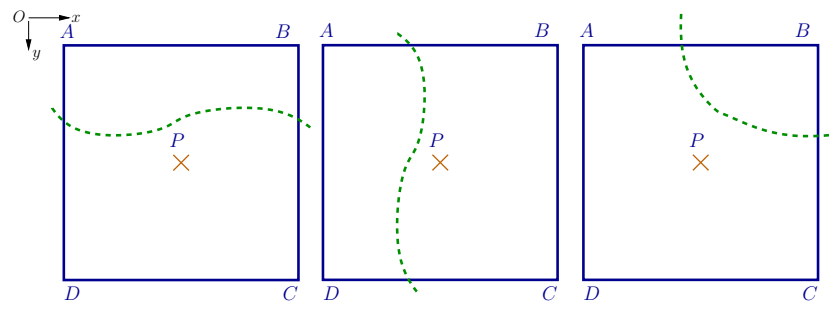

Figure 16. Different positions of a discontinuity in a subset 
As shown in Figure 16, the latter criterion permits to capture the discontinuity, whatever is its position in the subset. However, in case of elongations or distortions, a discontinuity is located whereas the deformation is continuous. Thus, this criterion of discontinuity in a subset is available if the elongations and the distortions stays lower than the displacements due to the discontinuities, namely in the case of brittle fracture.

\subsubsection{Implementation}

In this part, the method is performed on an artificial image deformed under an asymptotic displacement field.

Figure 17 shows a reference image (256x256 pixels) and the corresponding image deformed artificially under an asymptotic displacement field (pure mode 1 ). The crack tip is located in the reference image center $\left(\left(x_{t i p}, y_{t i p}\right)=(128,128)\right)$ but the end of the crack is not visible since the displacement is sub-pixel.

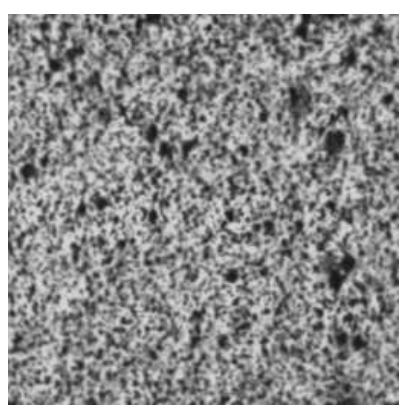

Reference image (256x256 pixels)

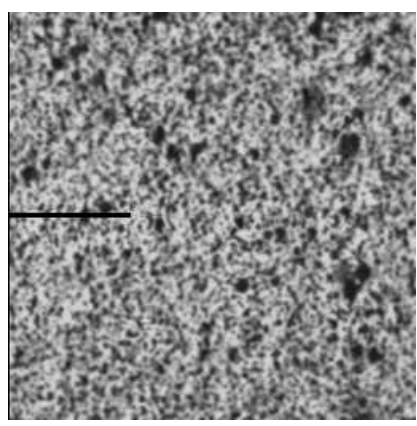

Artificial image deformed Pure mode 1

Figure 17. Reference image and artificial image deformed under an asymptotic displacement field (pure mode $\left.1,\left(x_{t i p}, y_{t i p}\right)=(128,128)\right)$

Firstly, the two images are loaded and the subset size is chosen (9x9 pixels) equal to the grid size corresponding to the position of the subset center. The grid is represented in Figure 20. Secondly, the criterion of discontinuity in a subset (Equation 11) is evaluated all over the image as shown in Figure 18. Thirdly, the latter criterion is thresholded: 0 for the sound subsets, 1 for the cracked subsets and -1 for the subset containing the crack tip as shown in Figure 19. Finally, the crack is represented on the deformed image by joining the cracked subset center positions balanced as shown in Figure 20. The crack tip position is $\left(\left(x_{t i p}, y_{\text {tip }}\right)=(126,126)\right)$. Since the grid is 9 pixels width, the resolution of the latter position is \pm 4 pixels. 


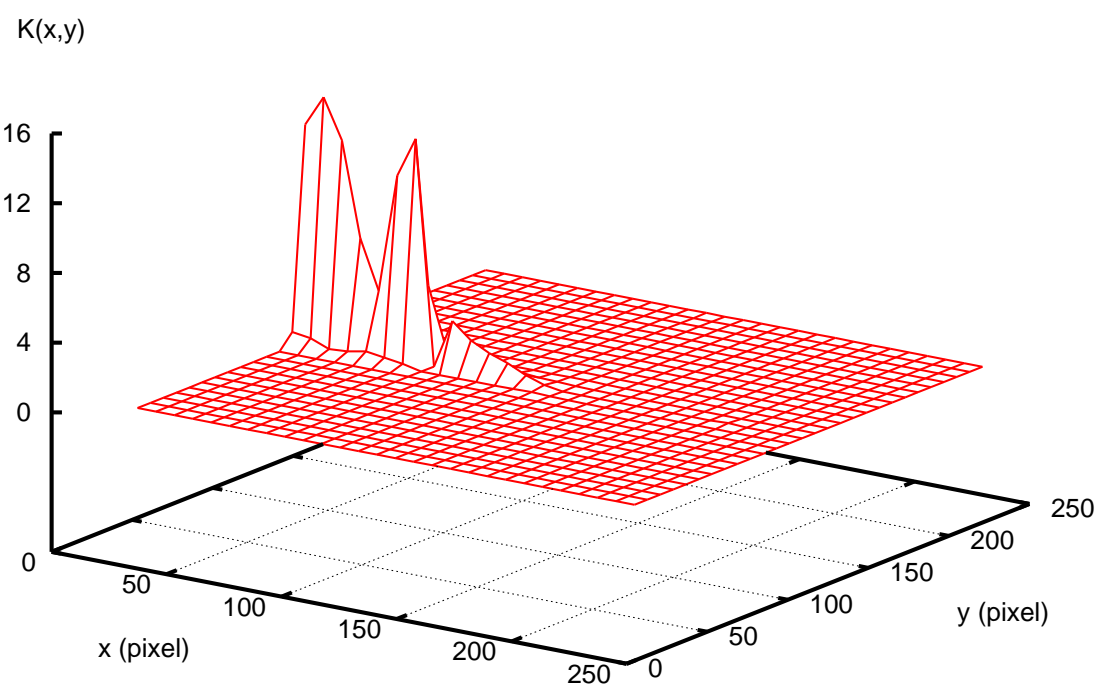

Figure 18. Criterion of discontinuity in a subset

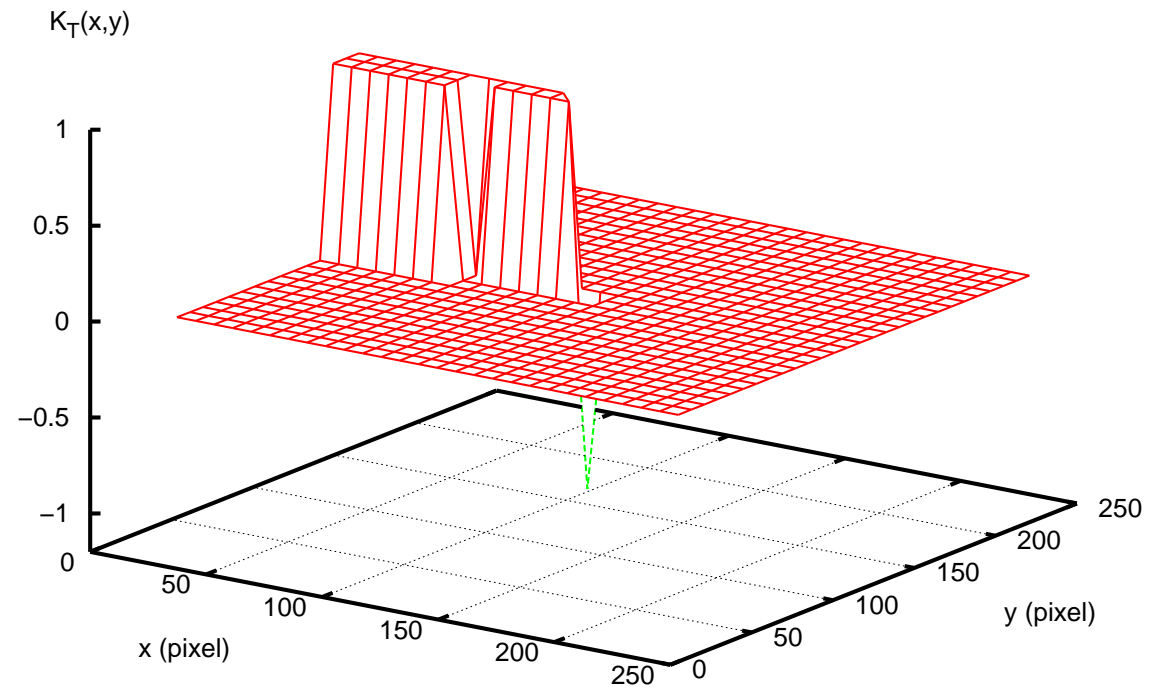

Figure 19. Criterion of discontinuity in a subset thresholded 


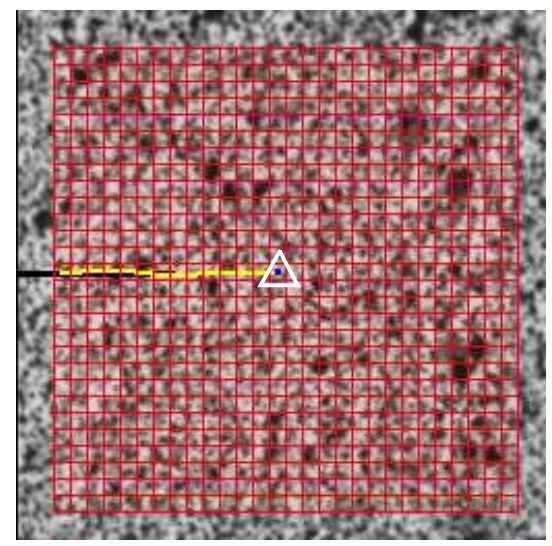

$\boldsymbol{\Delta}\left(x_{t i p}, y_{t i p}\right)=(126,126) \pm 4$ pixels

Figure 20. Result of the crack localization for the artificial test (subset: $9 x 9$ pixels, grid: $9 x 9$ pixels)

\subsubsection{Comparison with a standard digital image correlation tool}

In order to show the interest of the method developed, the vertical displacement estimated with a standard digital image correlation tool (Icasoft, developed by (TouchalMguil, 1997)) is shown in Figure 21 with the same grid and subset characteristics. Whereas the crack position can be localized in the sub-pixel discontinuous subset, the vertical displacement estimated on the subset containing a discontinuity larger than 1 pixel is absurd. Moreover, the crack tip position localization is very problematic with the standard method.

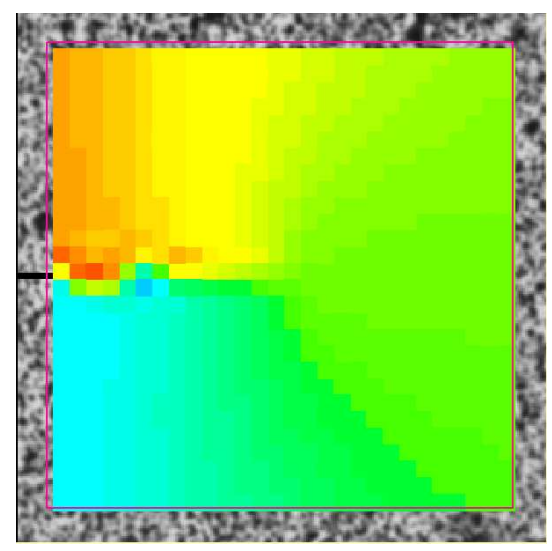

Figure 21. Vertical displacement estimated with a standard digital image correlation tool (subset: $9 x 9$ pixels, grid: $9 x 9$ pixels) 


\subsubsection{Influence of the grid size}

The same test is carried out with different grid and subset characteristics (subset: $6 x 6$ pixels, grid: $2 x 2$ pixels). The resulting crack position is shown in Figure 22. The crack tip position is $\left(\left(x_{t i p}, y_{t i p}\right)=(127,128) \pm 1\right.$ pixels $)$.

The theoretical crack position is $\left(x_{t i p}, y_{t i p}\right)=(128,128)$. As shown by Figure 20 and Figure 22, the finer is the grid, the better is the accuracy. Thus, the method developed is convergent and consistent.
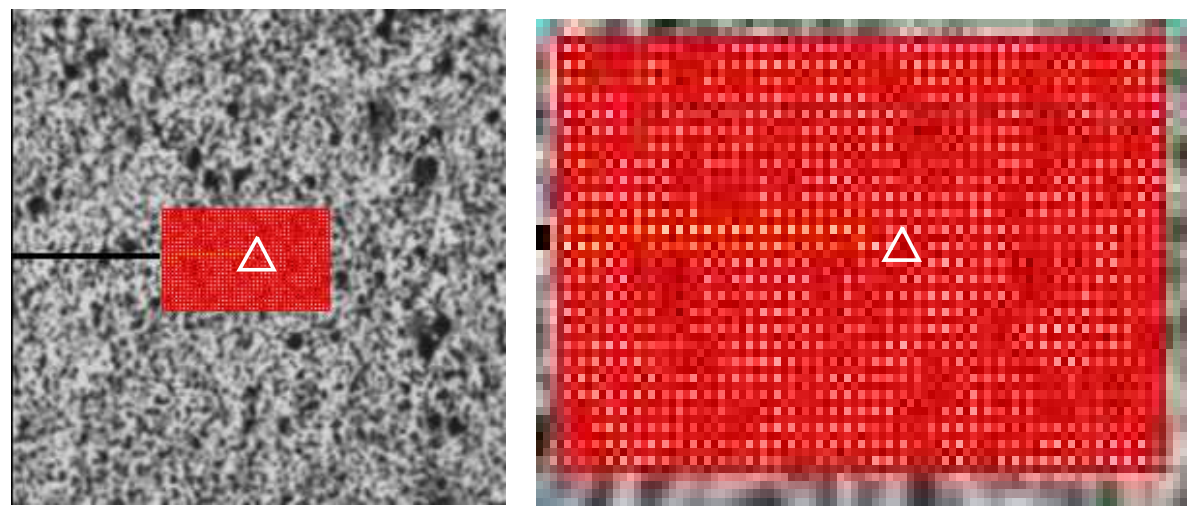

$\boldsymbol{\Delta}\left(x_{\text {tip }}, y_{\text {tip }}\right)=(127,128) \pm 1$ pixel

Figure 22. Result of the crack localization for the artificial test (subset: $6 x 6$ pixels, grid: $2 x 2$ pixels)

\subsection{Application: dynamic crack propagation under mixed-mode loading}

In this part, the method is applied on dynamic crack propagation experiment under mixed-mode loading.

\subsubsection{Experimental procedure (Test 3 )}

The specimen is similar to the specimen tested in part 2 on the SHPB (same material, same geometry). However, the specimen is now impacted by a fast jack and the initial notch is machined in order to increase the mixity effects at initiation. The specimen geometry is represented in Figure 23. The specimen is directly impacted by the fast jack and the compressive loading is converted into tensile loading in the vicinity of the initial notch by the circular hole. As developed by Grégoire et al. (2007), the crack initiation depends on the initial notch radius. The finer is the initial notch, the more similar is the crack before and after the initiation. Hence, a sharp notch is introduced at the tip of the pre-notch by tapping a razor blade. This technique was developed in (Saad-Gouider et al., 2006). 

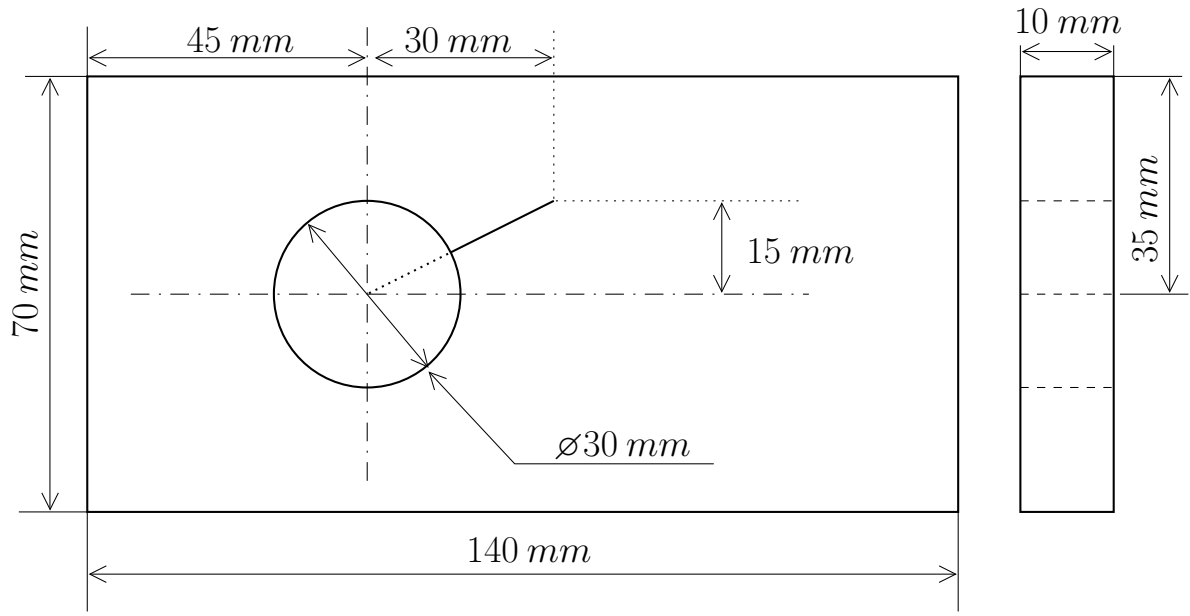

Figure 23. Specimen geometries under mixed-mode loading (Test 3)

The experimental test rig is sketched in Figure 24. One can identify:

- 1 fast jack (travel $<300 \mathrm{~mm}$, speed $<10 \mathrm{~m} / \mathrm{s}$ ) and its control unit;

- the specimen and a gage to detect the initiation;

- 1 optical sensor (Zimmer 200H) to control the displacement imposed;

- 1 load sensor connected to its amplifier;

- 1 data acquisition adapter ( 4 channels, $1 \mathrm{MHz}$ );

- 1 ultra-fast camera (Cordin 550-32, 1000x1000 pixels, 400000 frame/s;

- 2 flash units (Cordin 605);

- 3 computers.

The PMMA optical properties are not used and the specimen is speckled in order to use the digital image correlation technique. The ultra-fast rotating mirror camera is triggered by the breaking of a gage stuck ahead the initial notch and takes then 32 images of the crack propagation.

One experiment is carried out with a fast jack velocity of $10 \mathrm{~m} / \mathrm{s}$ and the crack propagation history is represented in Fig 25. The experiment duration is $200 \mu s$, the frame rate is $161616 \mathrm{frame} / \mathrm{s}$ and the duration between two frames is $6 \mu \mathrm{s}$. Since the specimen displacement is imposed, no crack arrest occurs during the propagation but the crack turns towards the symmetry axis corresponding to the maximum stress zone. The mean crack tip velocity is $500 \mathrm{~m} / \mathrm{s}$. 


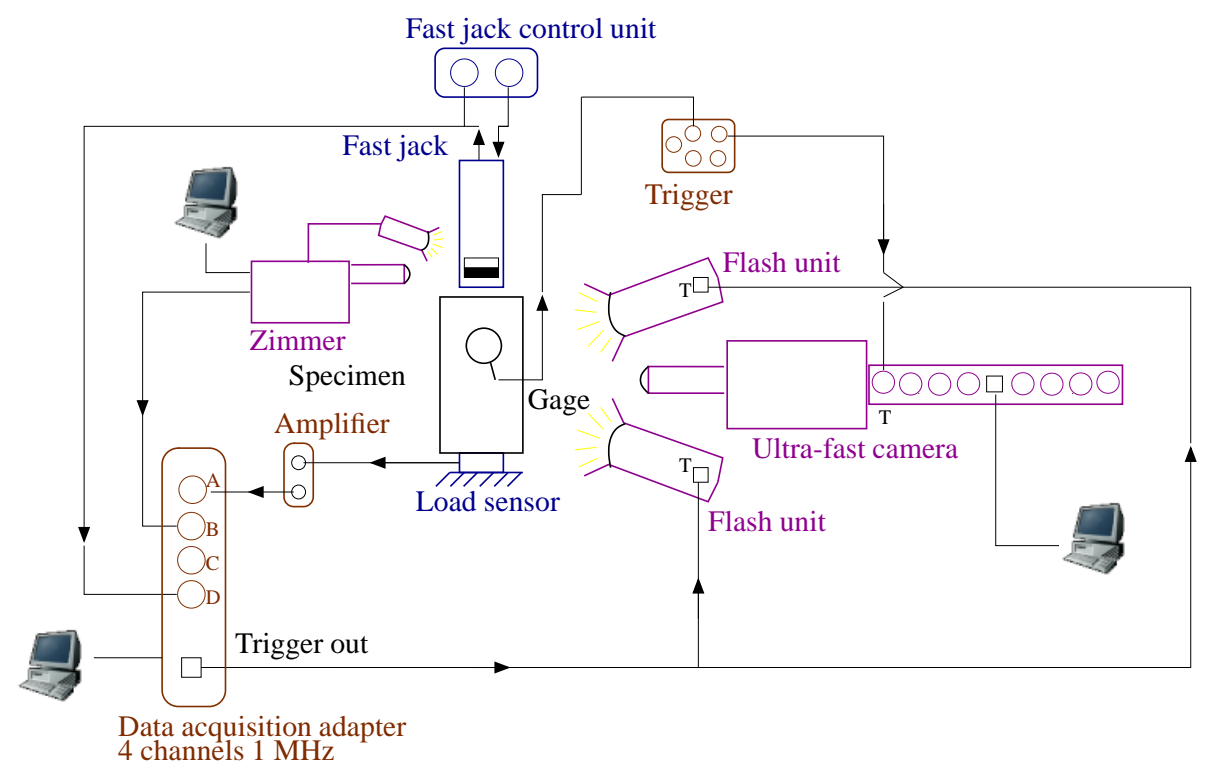

Figure 24. Experimental test rig (Fast jack)

\subsubsection{Crack localization}

Since there are 32 different CCD channels in the ultra-fast camera, the correlation cannot be carried out between two successive frames. A set of sound specimen frames is taken before the experiment in order to obtain the reference image for each CCD channel. The crack localization is thus performed between a reference image taken before the experiment and a deformed image taken during the experiment.

Fig 26 shows the crack localization results for the twentieth frame taken at the time $124 \mu s$. Different crack path results for different grid sizes are presented. This results show again the consistence and the convergence of the method. Nevertheless the Fig 26 points out that it is difficult to obtain accurately both the crack path localization and the crack tip position in case of mixed loading.

In the crack tip vicinity, the finer is the grid; the better is the accuracy (Fig 26f). It leads to a large number of subsets and the grid has to be coarser to localize the entirely crack path (Fig 26c and Fig 26d). Moreover, if the grid is finer than the crack opening, it leads to wrong results for the subset which are located between the crack lips. In case of pure mode I or straight crack propagation, the grid position can be adapted to minimize this effect. In case of dynamic crack propagation under mixed loading conditions, the phenomenon is increased and the grid size has to be chosen in order to have a good compromise between the localization of the entirely crack path and the crack tip position. 


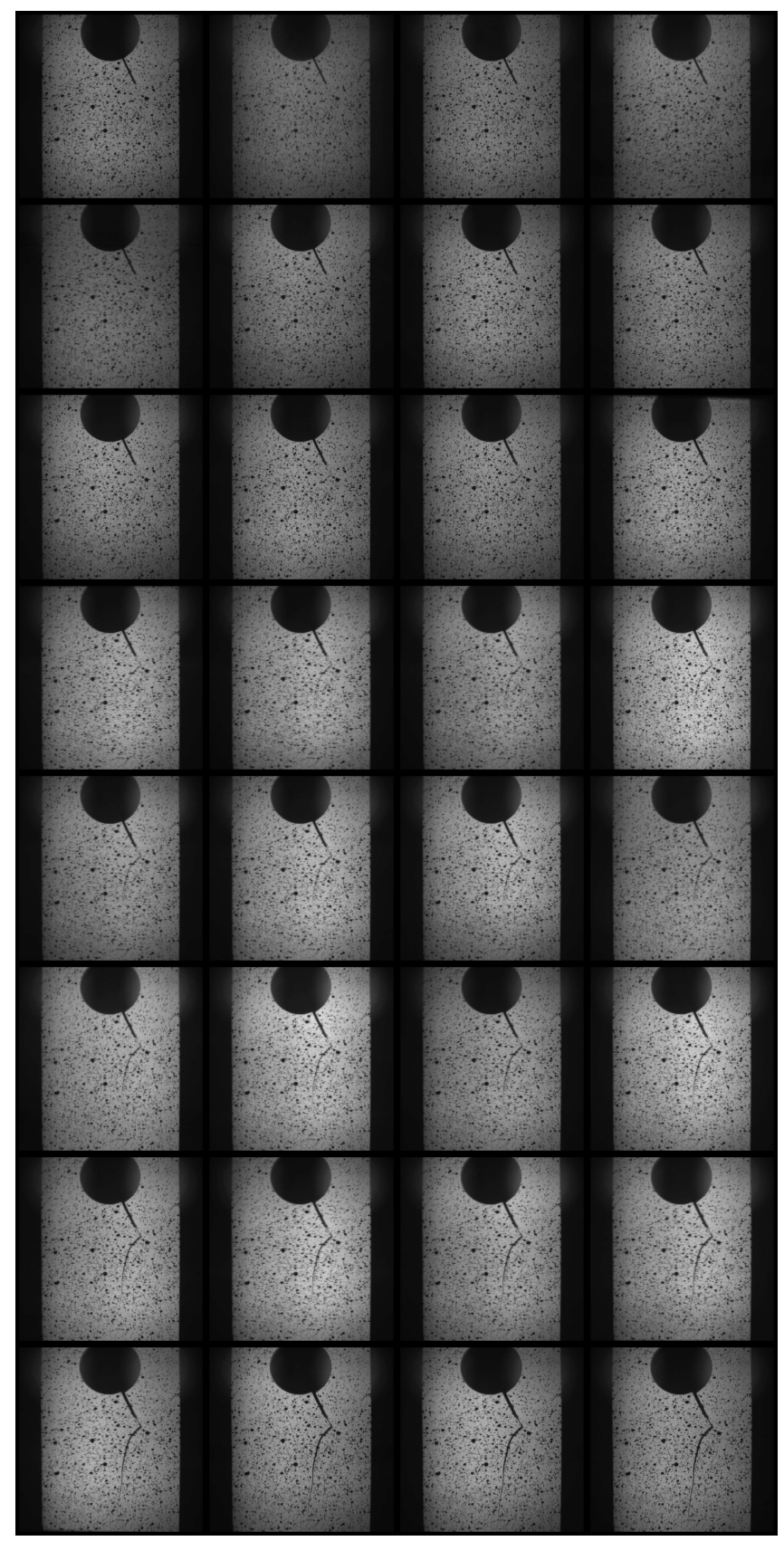

Figure 25. Crack propagation history for the test 3 


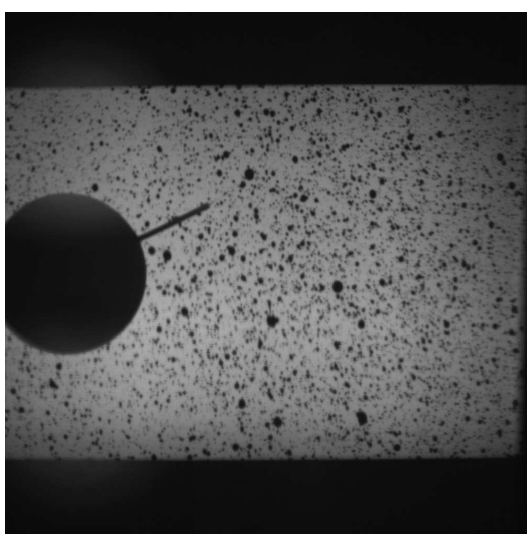

a) reference image

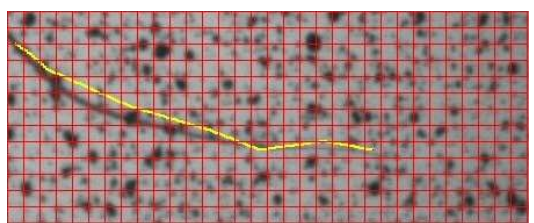

c) grid/subset: $15 \times 15$ pixels $\left(x_{\text {tip }}, y_{\text {tip }}\right)=(753,441) \pm 7$ pixels

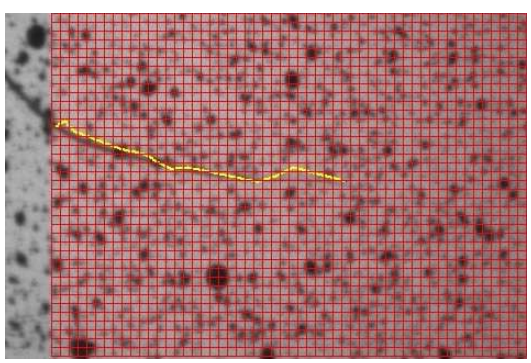

e) grid/subset: 9x9 pixels

$\left(x_{\text {tip }}, y_{\text {tip }}\right)=(751,441) \pm 4$ pixels

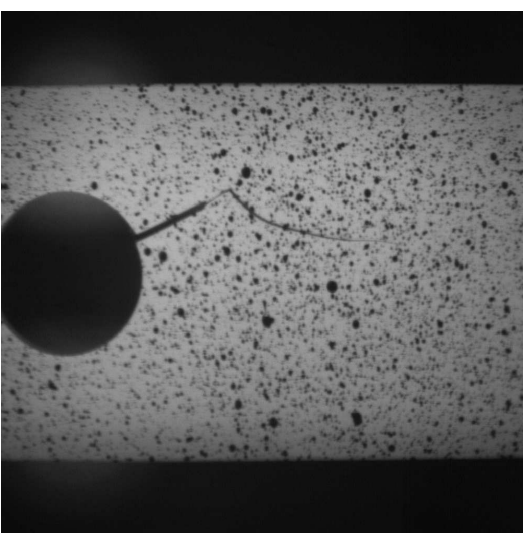

b) deformed image

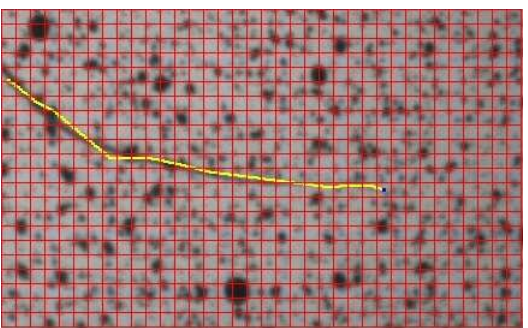

d) grid/subset: $12 \times 12$ pixels

$\left(x_{\text {tip }}, y_{\text {tip }}\right)=(756,444) \pm 6$ pixels

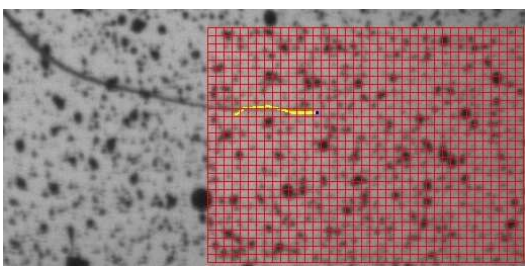

f) grid/subset: $6 x 6$ pixels

$\left(x_{\text {tip }}, y_{\text {tip }}\right)=(748,442) \pm 3$ pixels

Figure 26. Crack localization results for different grid sizes for the test 3

The dynamic conditions lead to other difficulties: the images cannot be all treated by the crack localization algorithm. As shown by Fig 25, the luminosity is not constant during the experimental test and it is not constant between the reference and the deformed images. The mean luminosity effects are corrected by using the cross correlation coefficient but there are moving light spots which penalize the correlation algorithm. 
All the 32 images have been treated by the crack localization algorithm. Figure 27 shows the propagating crack tip position history. In this figure, data are plotted with the error bars corresponding to the resolution of the crack localization algorithm for each image treated ( \pm 6 pixels corresponding to $\pm 0.28 \mathrm{~mm}$ ).

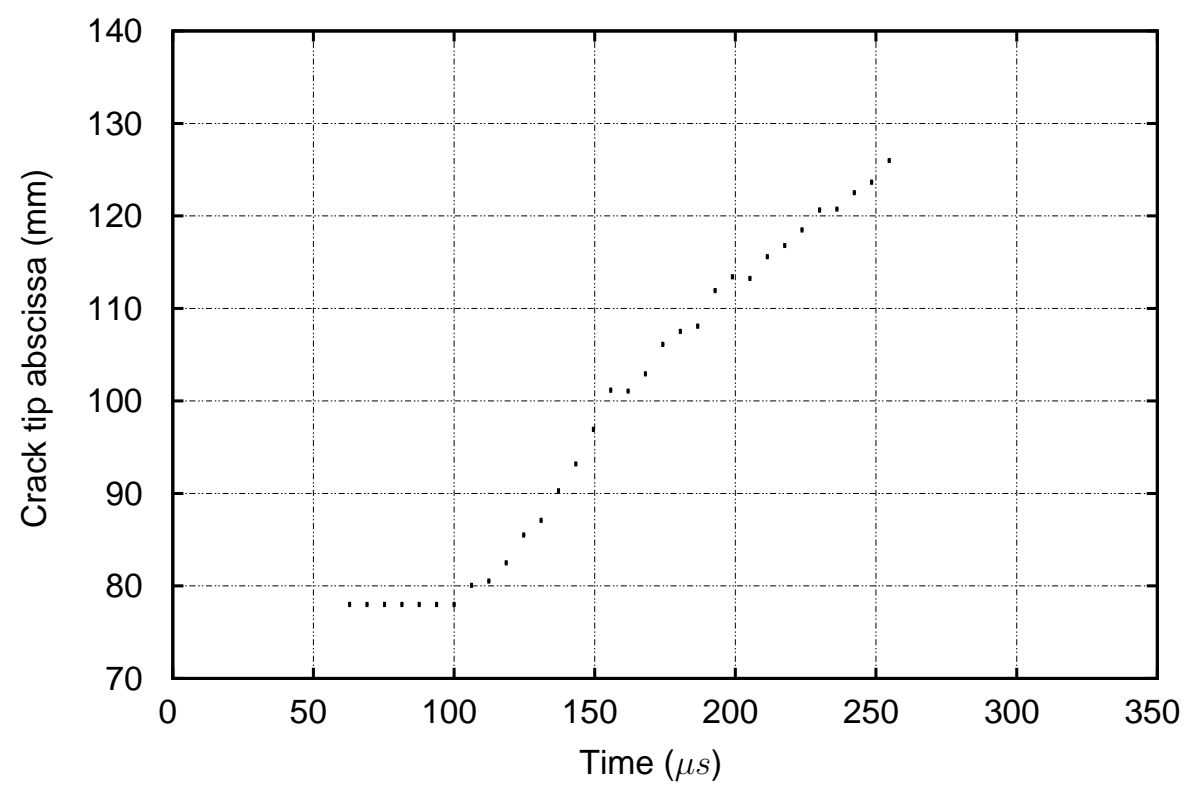

Figure 27. Crack tip position history for the test 3 (fast jack velocity: $10 \mathrm{~m} / \mathrm{s}$ )

\subsubsection{Numerical comparison}

This section presents the numerical comparison with the experimental results obtained for the test 3 .

The eXtended Finite Element Method (see the section 2.4) is still chosen for the simulation and the mesh still consists of 1377 four-node elements with 4 integration points. The mesh,the initial notch and the new boundary conditions due to the change of the test rig are shown in Fig 28. The numerical calculation requires 70 time steps with a step size chosen as $\Delta t=5 \mu \mathrm{s}$.

Since the crack initiates in mixed-mode, the mixity at the initiation is used to determine the dynamic crack initiation toughness $K_{1 d}$ as explained in (Grégoire et al., 2007). An initiation angle $\theta_{c}=76^{\circ}$ is measured on the postmortem crack path. Then, a numerical simulation of the dynamic response of the specimen with an initial fixed notch is performed and the evolutions of $K^{*}$ and $\theta^{*}$ (see Equation 1 and Equation 2) versus time are calculated. The value of $K_{1 d}=1.65 M P a \sqrt{m}$ is obtained. 


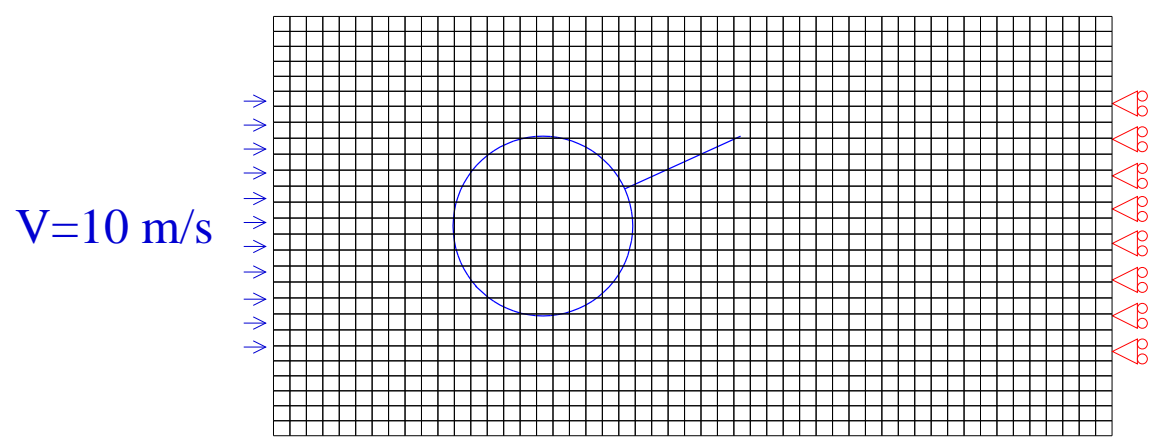

Figure 28. Mesh and initial notch and new boundary conditions for the test 3

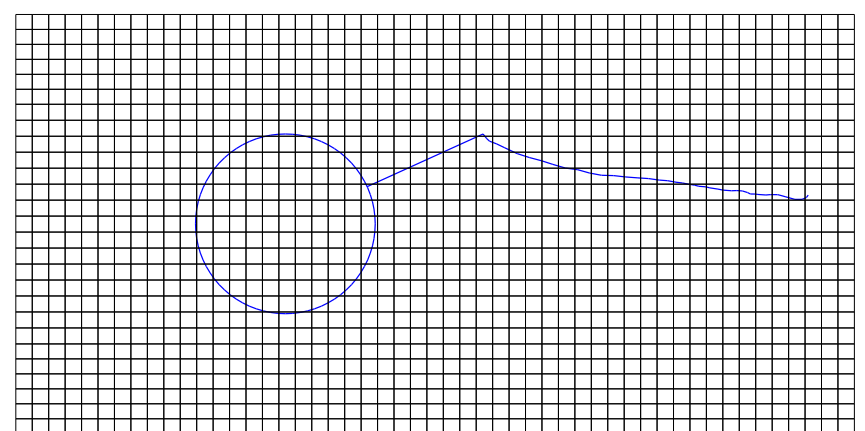

Figure 29. Mesh and numerical crack path for the test 3

The dynamic crack propagation criterion Equation 3 have been used with $K_{1 d}=$ $1.65 M P a \sqrt{m}$ and $K_{1 a}=1.25 M P a \sqrt{m}$.

The numerical crack path is shown in Figure 29 and Figure 30 shows the comparison between the experimental and numerical crack tip position histories.

On Figure 30.b, there is a good matching of the crack tip abscissa histories. However, if the crack turns towards the axis of symmetry (maximum stress zone) on Figure 29, the mixity seems more important on the experimental crack path (Fig 30.a) all over the propagation.

Finally, an automatic method based on full-field displacement measurement is developed for crack localization in brittle material whatever their opacity. 
a) Crack paths

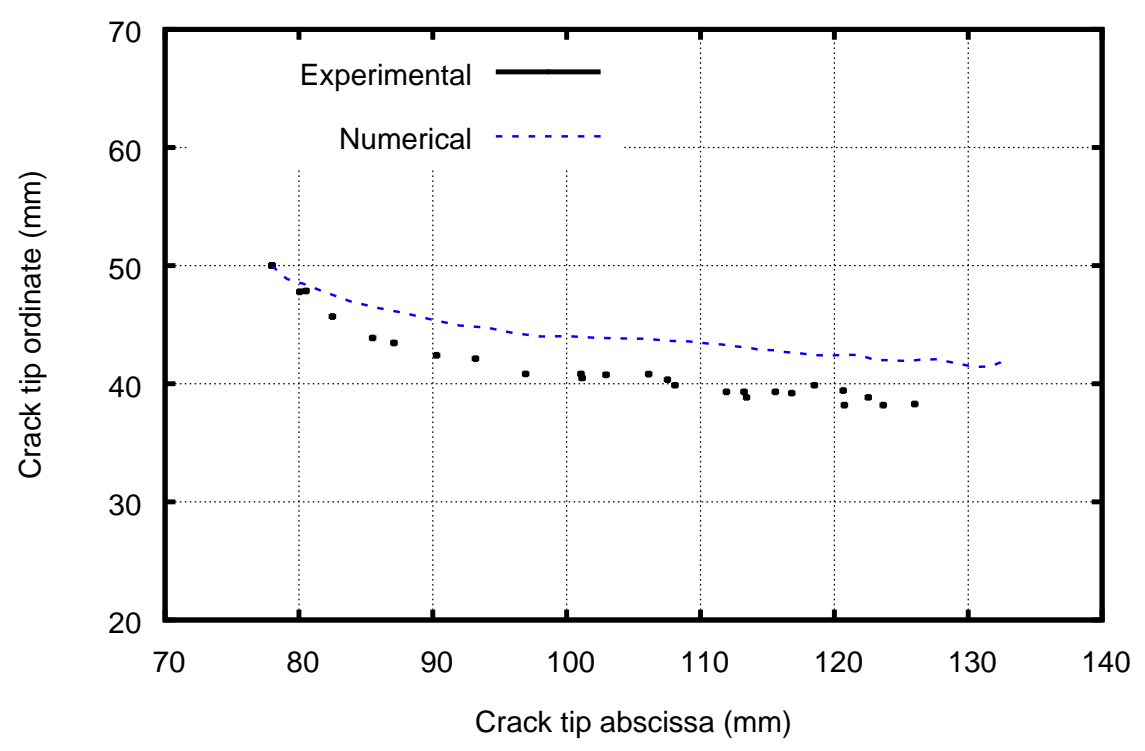

b) Crack tip position histories

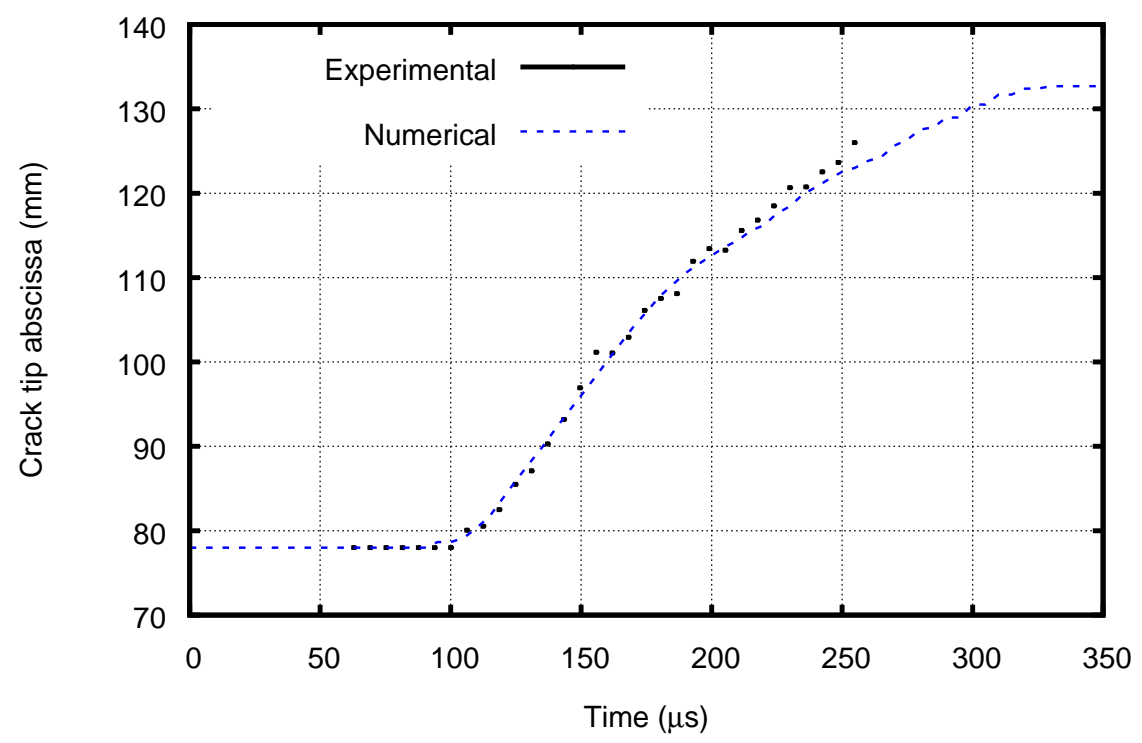

Figure 30. Comparison of the crack tip position histories for the test 3 


\section{Conclusion}

The two methods presented before permit the localization of a crack under both dynamic and mixed-mode loading. The method based on optical displacement sensors provides a highly accurate crack tip position history even in highly transient propagation phases as crack arrest and restart. It should be used for testing the reliability of numerical simulation tools and for assessing new loading rate dependant dynamic crack growth criteria.

Nevertheless this technique cannot be applied to non-transparent material. For these kinds of materials, another method based on digital image correlation has been presented. However the accuracy regarding the latter is lower, this method has the benefit to be based on full-field displacement measurement. Therefore, the algorithm could be improved to evaluate dynamic stress intensity factors directly from dynamic crack propagation experiments and a method for assessing dynamic crack growth criteria directly from experimental results could be developed.

\section{Acknowledgements}

We are grateful to the Laboratoire de Mécanique des Solides, École Polytechnique, France and the Département Aéroélasticité et Dynamique des Structures of the Office National d'Études et de Recherches Aérospatiales, Lille, France where the experiments of respectively Section 2.1 and Section 3.3.1 have been performed. This work was sponsored by the ANR/CNRS Grant DynRupt (JC05_45254).

\section{References}

Fineberg J., Gross S. P., Marder M., Swinney H. L., “Instability in Dynamic Fracture”, Physical Review Letters, vol. 67, n 4, p. 457-460, 1991.

Grégoire D., Maigre H., Réthoré J., Combescure A., “Dynamic crack propagation under mixedmode loading - Comparison between experiments and X-FEM simulations", International Journal of Solids and Structures, vol. 44, n² 20, p. 6517-6534, 2007.

Hild F., Réthoré J., Roux S., “ Measurement and identification techniques for evolving discontinuities", IUTAM Symposium on Discretization Methods for Evolving Discontinuities, 2006.

Kolsky H., " An investigation of the mechanical properties of material at a very high rate of loading”, Proceedings of the Physical Society, vol. B 62, p. 676-700, 1949.

Moës N., Dolbow J., Belytschko T., “ A finite element method for crack growth without remeshing”, International Journal for Numerical Methods in Engineering, vol. 46, p. 131-150, 1999.

Owen D. M., Zhuang S., Rosakis A. J., Ravichandran G., “ Experimental determination of dynamic crack initiation and propagation fracture toughness in thin aluminium sheets", International Journal of Fracture, vol. 90, p. 153-174, 1998. 
Ravi-Chandar K., Dynamic Fracture, Elsevier, 2004.

Réthoré J., Méthodes éléments finis étendus en espace et en temps: Application à la propagation dynamique des fissures, PhD thesis, INSA-LYON, 2005.

Réthoré J., Gravouil A., Combescure A., “ An energy conserving scheme for dynamic crack growth with the extended finite element method", International Journal for Numerical Methods in Engineering, vol. 63, p. 631-659, 2005.

Saad-Gouider N., Estevez R., Olagnon C., Seguela R., “ Calibration of a viscoplastic cohesive zone for crazing in PMMA”, Engineering fracture mechanics, vol. 73, n 16, p. 2503-2522, 2006.

Stalder B., Béguelin P., Kausch H. H., “ A simple velocity gauge for measuring crack growth”, International Journal of Fracture, vol. 22, n 2, p. R47-R50, 1983.

Sutton M., Cheng M., Peters W., Chao Y., McNeill S., “ Application of an optimized digital correlation method to planar deformation analysis", Image and Vision Computing, vol. 4, $\mathrm{n}^{\circ}$ 3, p. 143-150, 1986.

Sutton M., Wolters W., Peters W., Ranson W., McNeill S., “ Determination of displacements using an improved digital correlation method", Image and Vision Computing, vol. 1, n 3, p. 133-139, 1983.

Touchal-Mguil S., Une technique de corrélation d'images numériques: application à la détermination de courbes limites de formages et proposition d'un critère de striction, $\mathrm{PhD}$ thesis, INSA-LYON, 1997.

Zhao H., Gary G., " A three dimensional analytical solution of the longitudinal wave propagation in an infinite linear viscoelastic cylindrical bar. Application to experimental techniques", Journal of Mechanics and Physics of Solids, vol. 43, n 8, p. 1335-1348, 1995. 
